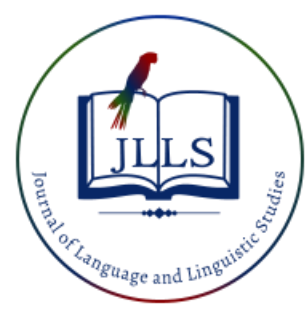

Available online at www.jlls.org

JOURNAL OF LANGUAGE

AND LINGUISTIC STUDIES

ISSN: 1305-578X

Journal of Language and Linguistic Studies, 17(1), 139-157; 2021

\title{
Blend formation in Turkish Sign Language: Are we missing the big picture?
}

\author{
Bahtiyar Makaroğlu a 1 iD \\ ${ }^{a}$ Ankara University, Ankara, Turkey
}

\section{APA Citation:}

Makaroğlu, B. (2021). Blend formation in Turkish Sign Language: Are we missing the big picture?. Journal of Language and Linguistic Studies, 17(1), 139-157. Doi: 10.52462/jlls.8

Submission Date: 08/01/2021

Acceptance Date: 17/03/2021

\begin{abstract}
From the point of word formation, the phenomenon of lexical blending is a common productive process, entailing the notion of combination of lexemes in so many languages. In the vast majority of literature on blends, they preserve a linear formation of segments with a shortening of both lexemes. However, in sign languages where morphological categories are mainly encoded by non-concatenative morphology, signed blends can be created by the general mechanism of templatic structures, the combination of lexical bases into a non-linear sequence. Specifically, the main purposes in this study are (i) to provide a comprehensive definition of blending formation in signed modality, (ii) to determine whether there are any structural regularities in the formation of lexical blends in Turkish Sign Language (TID), and (iii) to classify TID blends according to well-defined criteria. The corpus data to be studied currently include 109 blending formations. Overall, the results demonstrate that TID data has familiar properties of blends (named complete blends here) in established spoken languages, as well as modality-specific types of root, simultaneous and initialized blends. We propose a modality-specific categorization, in which blend formation is not limited to linear organization and actual source words.
\end{abstract}

Keywords: blending; sign languages; word formation; word creation; simultaneity

\section{Introduction}

Taking into account the morphological formation, one of the central questions in the field of sign language linguistics is the issue of sub-lexical systems in non-concatenative morphology, and how this relates to the process of word-formation in the signed modality. There is a growing body of literature proposed that SLs are similar to Semitic languages in exhibiting morphological [root + template] combinations (e.g. Brentari 2002; Sandler \& Lillo-Martin 2006; Belsitzman \& Sandler 2016; Makaroğlu 2018). Following this perspective, this paper argues that the use of templates in SLs provides a new window into both word formation and lexical blends. Although there have been a number of studies on the theoretical aspects of word formation in the field of SL linguistics to date (e.g., Meir, Aronoff, Sandler \& Padden 2010; Meir 2012), there remain relatively few exemplar-based approaches examining the characteristics of blending signs in non-concatenative morphology (e.g.

\footnotetext{
${ }^{1}$ Corresponding author.

E-mail address: makaroglu@ ankara.edu.tr
} 
Mirus et al 2012; Lepic 2016). Together, these studies begin to provide us with a cross-linguistic perspective on creative and productive properties of blending as a type of word-formation in SLs. Lepic (2016) has recently asserted that lexical blending is a kind of analogical process that hold for the morphological operations of both spoken and signed languages.

There have been so many attempts to describe derivational processes of TiD (e.g. Kubuş 2018; Taşçı 2012; Dikyuva, Makaroğlu \& Arık, 2017; Taş̧̧ı \& Göksel 2018; Makaroğlu 2020) but prior to the current research, as far as we know, no complete description has been done of the types of blends in TID. Keeping this necessity in mind, it has been expected that a categorization of TiD blends would be an interesting data to set to test the universal framework in blending formation and to advance derivational mechanisms in signed modality. The current approach here is both corpus-based and datadriven. On the basis of TID corpus data that will be published as open-access soon, this study aims to investigate the nature of blending formation and the role of lexical blends in SL morphology, offering a corpus-based sampling that shows a range of modality-specific features. Ultimately, the goal of this study is threefold: (i) to provide a comprehensive definition of blending formation in signed modality, (ii) to determine whether there are any structural regularities in the formation of lexical blends in TiD, and (iii) to classify TID blends according to well-defined criteria. In this study, we follow Lepic (2016) for the classification blending formation in SLs but propose a slight revision for the types of lexical blends attested in our database.

The paper is organized as follows: Section 2 introduces the study of lexical blends in both spoken and signed languages through the panoramic description; in Section 3 the corpus data employed for the analysis as well as the methodology of TiD Corpus are presented; Section 4 outlines the lexical blending categories evaluative strategies attested (Section 4.1 describes complete blends, Section 4.2 root blends, Section 4.3 initialized blends, Section 4.4 simultaneous blends). Section 5 contains formal properties of blending formation, specifically of prosodic structure and phonological process in Section 5.1, the iconic motivation in a linguistic perspective in Section 5.2 and alignment of base words in Section 5.3. In section 6 some conclusions are drawn.

\section{Lexical Blends}

At first glance, a prototypical case of lexical blends is a one-word unit formed from the structural fusion of two (or possibly more) lexemes (e.g. a typical example, breakfast + lunch $=$ brunch). First, a blend formation is phonologically shortened (i.e. stressed like one phonological lexeme and reduced before being blended) (Bauer, Lieber \& Plag 2013) and distinguished from a compound in that it is combined with parts of words, rather than the whole words (Kemmer 2003:75). In other words, a blend is subject to a segmental reduction affecting both source constituents by applying phonological rules. As proposed by Bat-El (1996), semantically, a blended word conveys the concept of the (at least) two source words. Also, it is generally accepted that a lexical blend is created intentionally and consciously for various communicative or specific purposes (e.g. 'covidiot' is the fusion of 'covid' and 'idiot' and it refers to a person who ignores the official warnings regarding public health and refuses to follow 'Social distancing' during COVID-19 pandemic). In particular, the blend formation may be regarded as part of linguistic creativity of language users, that is, the formation of blends characteristically attribute to extra-grammatical process that is commonly classified as "morphological creativity" rather "morphological productivity" within the grammatical morphology framework (see Dressler 2000; Mattiello 2013). Accordingly, blending formation is commonly regarded as part of word-creation, rather than a regular word-formation process.

As stated above, the notion of lexical blending commonly indicates "creative technique" (Ronneberger-Sibold 2008) that refers to the creation of new words by fusion of certain parts of source 
words. However, recently descriptions using analogical model and analyses of this phenomenon in the semantic process of generalization have revealed that a blending element, for example -(a) holic in English, may become fully a productive morpheme used in various actual lexemes such as workaholic, computerholic, chocoholic, shopaholic etc. (Mattiello 2013, 2019). These (sub) regularities of blends also create small lexical families and share phonological analogy (Mattiello 2019) and prosodic structure (Arndt-Lappe \& Plag 2013). Note that as shown in (1), instances of splinters carry not only creativity but also productivity in diachronic process.

$\begin{array}{ll}\text { Splinters } & \text { Origin } \\ \text {-(t)arian } & \text { vegetarian } \\ \text {-burger } & \text { hamburger } \\ \text {-kini } & \text { bikini }\end{array}$

\section{Examples}

flexitarian, nuratian, breatharian, fruitarian

chickenburger, cheeseburger, beefburger

monokini, burkini, trikini

Interestingly, some examples of these splinters clearly show that analogical formation is the underlying process of blending, in that non-morphemic parts of a word combine with other words in paradigmatic substitution (Bauer et al 2013, Mattiello 2017). Parallel to these blending families, following the UK-wide referendum in 2016, various blends including shared prototype word -exit having the particular meaning 'withdrawal from the European Union - were created by means of direct analogy (e.g. Spexit $<\mathrm{Sp}($ ain $)+$ (exit), Nexit $<\mathrm{Ne}$ (therland) + (exit), Italexit $<$ Ital(ai) + (exit) etc.). Also, it is known that these creations usually share similar forms and meanings.

Building on this view, many scholars emphasize that blends are a major part of neologism in many domains: (i) in well-known trademarks, blends play a decisive role in innovative formation of brand naming practices (Jeremić \& Josijević 2019), (ii) political media is used to enhance the attentioncatching and thought-provoking properties of blends for politicized communities (e.g. Merkozy< Mer(kel) + (Sar)kozy) (Beliaeva 2019), (iii) blends display a variety of imaginative and unpredictable constructions in humorous literary texts (Lehrer, 2007).

In the domain of morphology, even if lexical blend constructions share powerful cross-linguistic similarities both in their analogical processes, this study suggest that spoken and signed languages differ from each other in terms of structural properties. Thus, it can easily be argued that the main reason for this difference is the morphological structure of signed languages: sequential and simultaneous. Because SLs display these two radically different realizations - morphological categories are encoded by non-concatenative morphology — in their grammar (c.f. Aronoff, Meir \& Sandler 2005). Because of modality specific aspects, sign languages have a strong tendency for simultaneous presentation of distinct units (e.g. classifier constructions, verb agreement) from phonology to morphology. That is to say that, it is also expected that they possibly differ from each other due to the cross-modal effects.

\section{Methodology}

The study reported in this paper draws on descriptive data that was taken as a part of TiD Corpus (Dikyuva et al 2017) which consists of approximately 6240 minutes of digital video recordings, collected from 116 native TiD signers from 26 different cities across Turkey. Aged between 12 and 60 , the participants were deaf $(\geq 75 \mathrm{~dB}$ pure-tone average in the better ear, confirmed by their audiometric test reports) from birth or who lost their hearing between the ages of 0 and 3 , and exposed to sign language in their earlier ages. All participants stated that they had daily contact with TiD in the Deaf community for more than 10 years (see discussion for signers' qualifications in linguistic research, Mathur \& Rathmann, 2006). Due to both financial and methodological constraints, less than $30 \%$ of the TiD Corpus (approximately 240,000 sign tokens) has to date (June, 2020) been transcribed 
(i.e., ID-gloss etc.) by the Deaf research assistants using ELAN annotation tool (http://www.latmpi.eu/tools/elan/). In this preliminary study, our database consists of 109 lexical blends that was collected from the TID Corpus, made up of various phonological formations.

\section{Types of Lexical Blend in TiD}

Cross-modal comparisons of blends are challenging because of the varied criteria and terms mostly based on spoken languages. Again, a comprehensive categorization of blend types in SLs has not been completed. As expected from the fact that it is possible to find different types of blending formation in the data from signed modality. As pointed out in previous studies (e.g. Mirus et al 2012; Lepic, 2016) on blending constructions, some phonological aspects of one source sign are combined with some phonological aspects of another source sign to form a new sign. Although some scholars disagree on the distinction between signed blends and compounds, this morphological operation fundamentally differs from compounding in that limited phonological properties of each sign appear in the lexical blend. So, there is no complete source sign in the output blend because of the spreading of phonological elements of each source sign. Contrary to compounds (Sandler \& Lillo-Martin 2006:226), they also have to reduce to a monosyllabic form. From the perspective of lexical categories, the source words do not hold the same feature properties in signed blends. In the corpus data we attested the various instances such as [noun + noun], [noun + adjective], [adjective + verb] etc. For an illustration, consider the following cases (1):

(1) a. NN combination

GUIDE + TOUR > GUIDED-TOUR

[22:002 S:00:03:15 E:00:03:16] $]^{2}$

b. NN combination

HOME + CLOSE > NEIGHBOUR

[34:019 S:00:06:41 E:00:06:42]

c. NN combination

READY + TAKE >CONVENIENCE-FOOD

[10:015 S:00:06:56 E:00:06:57]

On the basis of the blend properties in TiD Corpus, it can be easily argued that limited or no phonological similarity in manual parameters (i.e. handshape, movement etc.) is enough to motivate formation of a signed blend. However, sometimes overlapping segmental units may include more than one phonological feature. For example, in WRITTEN-COMMUNICATION, the source words, SENTENCE and COMMUNICATION, both share the same handshape (i.e ASL-9) and location (i.e. neutral space). Although the semantic considerations of lexical blending are beyond the scope of the current study, the meaning of blends are often compositional against to mostly (but not always) non-compositional compounds.

The analysis of TiD blends with respect to their formational properties on Lepic's (2016) categorization to a great extent but it has been complemented with other types. Thus, extending Lepic's classification (2016), we can distinguish various signed blend types in the TID Corpus, and categorize them with the properties of source units. Now let us introduce the blend types that emerged from our database.

\subsection{Complete Blends}

To briefly characterize the type of lexical blend, phonological parts of two fully lexicalized source words combine as in spoken languages (e.g. web + seminar > webinar). The examples in (2) are

\footnotetext{
${ }^{2}$ [plate number/city code: file code S:hour:minute:second E:hour:minute:second]
} 
known under the category of 'complete blend'. They are derived from at least two existing signs by combining in non-linear sequence. Similarly, lexical blends in spoken languages combine phonological parts of the source. In this respect, the TiD pattern fits into broader typology of blends in spoken languages where actual and lexicalized source words create blending forms. Consider the examples given in (2):

$\begin{array}{llll}\text { (2) Sign } 1 & \text { Sign } 2 & \text { Blend } & \\ \text { HOME } & \text { CLOSE } & \text { NEIGHBOUR } & \text { [34:019 S:00:06:41 E:00:06:42] } \\ \text { YEAR } & \text { BEFORE } & \text { OLD } & \text { [01:010 S:00:05:32 E:00:05:34] } \\ \text { SIMILAR } & \text { CIRCLE } & \text { REPETITION } & \text { [10:002 S:00:06:16 E:00:06:17] } \\ \text { GUIDE } & \text { TOUR } & \text { GUIDED-TOUR } & \text { [72:002 S:00:04:42 E:00:04:44] } \\ \text { SHORT } & \text { ANSWER } & \text { SHORT-ANSWER } & \text { [16:002 S:00:05:22 E:00:05:23] } \\ \text { MONEY } & \text { MUCH } & \text { EXPENSIVE } & \text { [42:005 S:00:07:36 E:00:07:37] } \\ \text { READY } & \text { TAKE } & \text { CONVENIENCE-FOOD } & \text { [10:015 S:00:06:56 E:00:06:57] }\end{array}$

Note that, it can be seen from the examples of complete blend in (1) that correspondence relationships between the blend and its source words involve manual segments. However, the identification of source signs in blends are not always obvious. For example, consider NEIGHBOUR, the sign is formed by combining the handshape of the sign HOME with the movement (i.e. away from body) of the sign CLOSE. The formation of phonological elements of this blend can be schematized as in Figure 1.

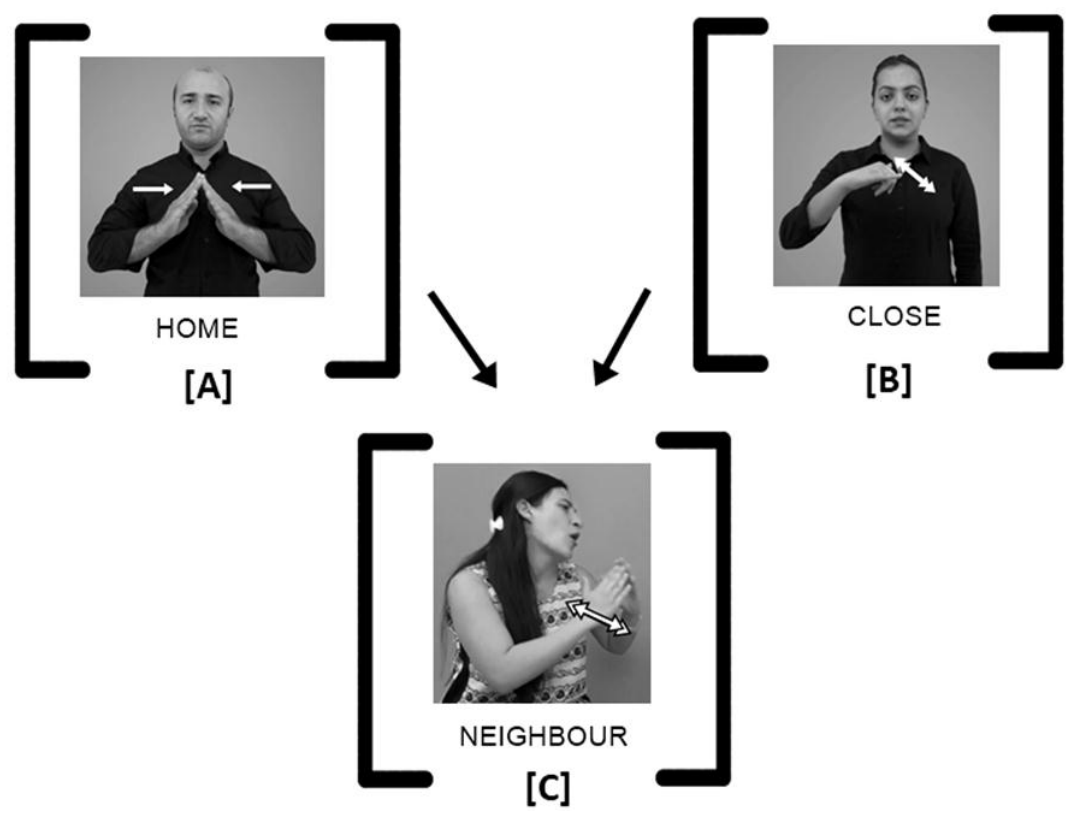

Figure 1. The TíD signs (a) $\mathrm{HOME}^{3}$ and (b) $\operatorname{CLOSE}^{4}$ combine to form the blend (c) NEIGHBOUR ${ }^{5}$

These phonological correspondences between HOME, CLOSE, and the blend NEIGHBOUR can be structurally represented as in Figure 2, where manual parameters (i.e handshape, location and movement) are listed for each signed word. Here, this can be formally presented as HOME (Figure 2a)

\footnotetext{
${ }^{3}$ HOME, Makaroğlu \& Dikyuva (2017) http://tidsozluk.net/vidz_proc/0073/degiske/73-01_cr_0.5.mp4 ${ }^{4}$ CLOSE, Makaroğlu \& Dikyuva (2017) http://tidsozluk.net/vidz_proc/0306/degiske/306-01_cr_0.5.mp4 ${ }^{5}$ NEIGHBOUR, TID Corpus [34:019 S:00:06:41 E:00:06:42]
} 
and NEIGHBOUR (Figure 2c) being signed with similar handshapes (HS), and CLOSE (Figure 2b) and NEIGHBOUR being articulated with the same movement (MOV) patterns. Also, both source words (i.e. HOME and CLOSE) and blend share exact formational location (LOC) value.

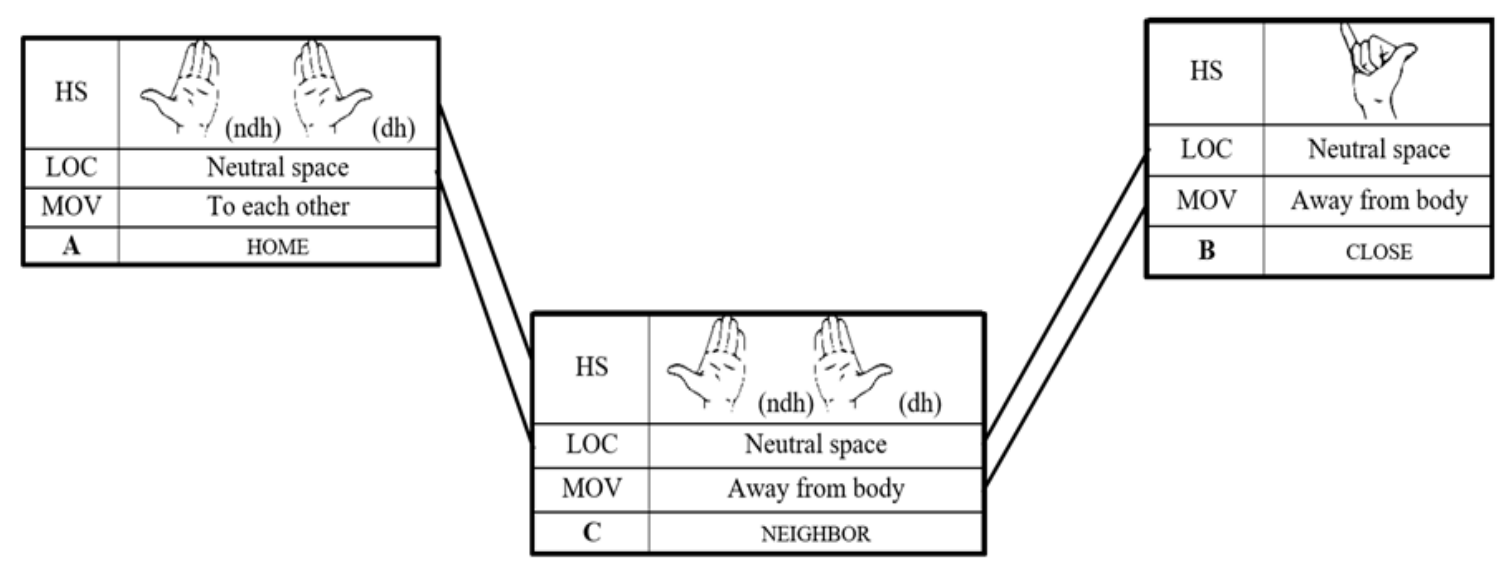

Figure 2. Phonological elements of the TID signs (a) HOME and (b) CLOSE combine to form the blend (c) NEIGHBOUR

Although complete blends are not discussed within the scope of productivity in Lepic's study (2016), our dataset clearly show that certain sign parts can be defined to be productive in creating new words as in spoken languages (e.g. -(a) holic in English). For example, a splinter "upward palm orientation" originated from the sign OLDER creates new blends such as OLDER-BROTHER ${ }^{6}$ and OLDERSISTER $^{7}$. In such formations, blends share similar form and meaning as well.

\subsection{Root Blends}

As opposed to complete blends, a prototypical case of "root blends" is formed with the structural fusion of a fully lexicalized sign and an abstract $\operatorname{root}^{8}$ (i.e. location) with specific meaning. In other words, only one of the source units is an actual word having pronounceable/signable phonological content. In addition, the relationship of the actual word and location (named root here) is problematic for the general framework of blending formation. For this reason, we can assert that the root can be analysed more consonant like, similar to non-concatenative languages. Thus, root blends are formed by changing the location of actual source words but reusing the HS and MOV element of the lexicalized sign. Under this analysis, root blend DREAM as seen in Figure (3) is formed by combining the HS and MOV of the sign MAGIC with the (head) root having a semantic core related to a 'mental activity'.

\footnotetext{
${ }^{6}$ OLDER-BROTHER, TİD Corpus [06:004 S:00:05:52 E:00:05:53]

${ }^{7}$ OLDER-SISTER, TID Corpus [35:008 S:00:09:56 E:00:09:57]

${ }^{8}$ Following Templatic Morphology (see McCarthy 1979, 1981), root is not signable on its own and also lacks a fixed or precise semantic interpretation but acquire various interpretations when they combine with different nominal and verbal patterns.
} 


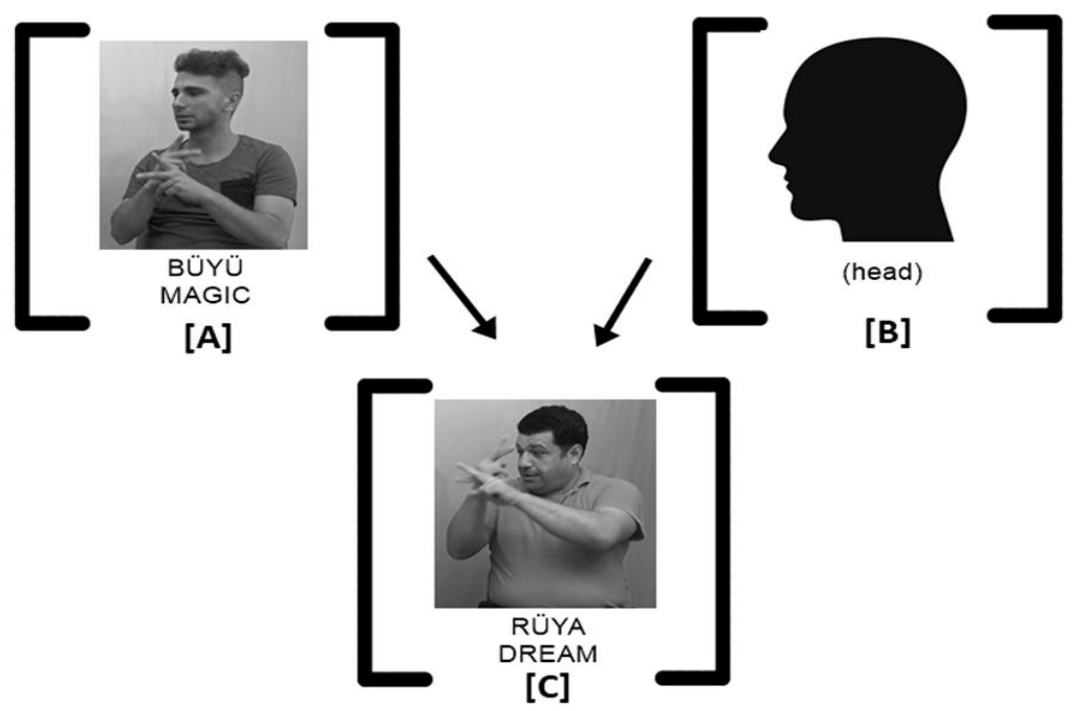

Figure 3. The TID sign (a) MAGIC ${ }^{9}$ and (head) root combine to form the blend (b) DREAM ${ }^{10}$

In this type of blending, the abstract root presents some feature of the related concept in an iconic way. Various marked locations in SLs have strong connotations and they construct a family of signs to be formed around them (Fernald \& Napoli, 2000). Also, the fact of word families regarding lexical blends have a robust impact on signed lexicon. Thus, this analysis suggests that the semantic content of the root blend is partially predictable by the nature of the location (e.g. eye location related to seeing). When lexical signs are combined with abstract root to create a blend, the meaning of the resulting blend is often transparent. In derivational context, it is easily asserted that this blend type is not limited to a specific location and is a productive word-creation process compared to other blend types in TID. This mean that the root blend formation may be regarded as a part of linguistic creativity of sign language users. (3) lists the TID blends that show a location-sign relationship.

$\begin{array}{llll}\text { (3) Sign 1 } & \text { Sign 2 } & \text { Blend } & \\ (\text { Head }) & \text { EMPTY } & \text { GOOFY } & {[01: 010 \text { S:00:07:37 E:00:07:38] }} \\ & \text { QUESTION } & \text { UNCERTAINTY } & {[06: 013 \text { S:00:05:00 E:00:05:01] }} \\ & \text { IMPORTANT } & \text { PROFESSOR } & {[06: 013 \text { S:00:02:21 E:00:02:22] }} \\ & \text { MAGIC } & \text { DREAM } & {[33: 006 \text { S:00:01:30 E:00:01:31] }} \\ & \text { ZERO } & \text { IGNORANT } & {[42: 009 \text { S:00:08:03 E:00:08:04] }} \\ & \text { FIRE } & \text { MISERABLE } & {[26: 011 \text { S:00:06:23 E:00:06:25] }} \\ & \text { REVERSE } & \text { DECEPTION } & {[34: 002 \text { S:00:00:19 E:00:00:20] }} \\ & \ldots & \ldots & \\ (\text { Nose }) & \text { EMPTY } & \text { DISAPPOINTMENT } & {[34: 019 \text { S:00:04:09 E:00:04:10] }} \\ & \text { PROGRESS } & \text { HABIT } & {[33: 012 \text { S:00:01:56 E:00:01:57] }} \\ & \ldots & \ldots & \\ (\text { Eye }) & \text { FINDING } & \text { PERCEPTION } & {[34: 004 \text { S:00:02:32 E:00:02:34] }}\end{array}$

${ }^{9}$ MAGIC, TID Corpus [42:010 S:00:09:48 E:00:09:49]

${ }^{10}$ DREAM, TID Corpus [33:006 S:00:01:30 E:00:01:31] 


$\begin{array}{llll} & \text { REVERSE } & \text { ILLUSION } & {[34: 017 \text { S:00:02:16 E:00:02:17] }} \\ & \ldots & \ldots & \\ \text { (Mouth) } & \text { LOCK } & \text { SECRET } & {[36: 003 \text { S:00:02:12 E:00:02:13] }} \\ & \text { HOLD } & \text { STUFFY } & \text { [01:007 S:00:07:37 E:00:07:39] } \\ & \ldots & \ldots & \end{array}$

It can be easily seen in (3) that (head) is the productive location in derivational process of TiD and signs having this parameter are often associated with "cognition" similar to other SLs. Also, the (mouth) is the location of signs related to speech. Many times, it is difficult to distinguish between blending and compounding. For example, in TID, the signs SATURDAY and SUNDAY each have repetitive movements (i.e. SATURDAY, internal movement of the hands and SUNDAY, path movement), respectively. When these two signs come together to form the disyllabic WEEKEND, the repetitive movements in both signs are dropped and replaced by a single movement (Dikyuva et al 2017:102). Again, in blending constructions, some of the phonological properties of each source sign appear in the output blending sign. In terms of alignment of based words, it is not possible to see one source sign followed by a second one (i.e at least two-syllable structure).

\subsection{Initialized Blends}

From the point of SL morphology, the phenomenon of initialization - initialized signs are widespread forms in signed lexicons, entailing the modification of fingerspelling alphabet in wordformation process. This process also is one of the most common derivational strategies that is used to borrow Turkish words into TID lexicon (see Kubuş 2008; Taşçı \& Göksel 2014; Dikyuva et al 2017). Consider the following examples in TID, signs such as LAZIM (NECCESARY), LİSE (HIGHSCHOOL), and LOKAL (CLUB) are derived from the fingerspelled letter L, which is borrowed from written Turkish words with the same meanings.
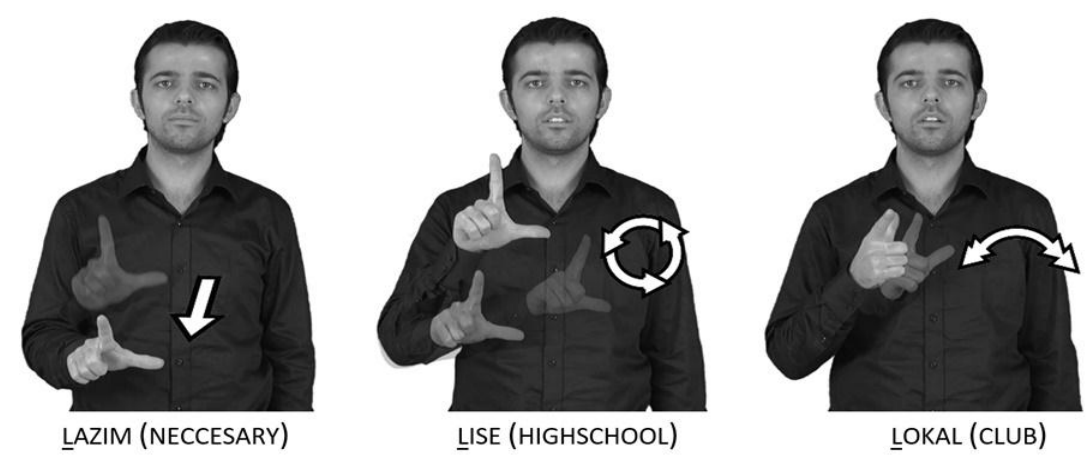

Figure 4. Initilazed signs LAZIM (NECCESARY), LISE (HIGHSCHOOL), and LOCAL (CLUB) in TİD (Dikyuva et al 2017:25)

In addition, roots in initialized signs do not have a marked location (e.g. nose, head), so they appear in neutral space; this implies that the roots in TiD take the neutral-space location by default (Makaroğlu 2018). Again, location is widely known to form a possible iconic parameter of lexical signs. So, it can easily be asserted that locations are directly or metaphorically related with a certain meaning (Östling et al 2018). These in turn raise the question of which description can be said to analyse the initialized sign with marked locations. As for morphological formation of manual alphabet which we focus on in this study, it can be seen that the classical 'initialized sign' term has a number of theoretical as wells as empirical gaps, one of which being the fact that there is no structural difference 
between initialized signs regardless of their location properties which can be directly related to semantic relations.

Note that, although we generally follow the construction-based analysis of Lepic (2016), the structure of initialized signs are not based on the phonological domain of an existing, actual TID sign. In addition, attempting to break initialized signs such as LAZIM (NECESSARY) down into independently meaningful pieces (i.e. manual alphabet and actual word) does not present any native sign in its structure. Therefore, what we call the structural fusion of a native sign and a fingerspelling alphabet is 'initialized blends' in our classification. So, initialized categories are categorized following the formbased criteria. Having noted the differences between our initialization classification (i.e. namely initialized signs and initialized blends) and that of Lepic, for example, the ASL blends FAMILY, ASSOCIATION, TEAM, and DEPARTMENT derived from the combination of the movement and location parameter of the source sign GROUP and the first FAs of related English words (Meir 2012). Let us now take a closer look at each case with examples from our database (4).

(4) FS

$\begin{array}{lll}\mathrm{P} & \text { MIND } & \text { PSYCHOLOGY (PSIKOLOJi) } \\ \mathrm{P} & \text { SUCCESS } & \text { POINT (PUAN) } \\ \mathrm{V} & \text { BODY } & \text { VITAMIN (VITAMIN) }\end{array}$

[26:016 S:00:01:49 E:00:01:50]

[01:009 S:00:03:40 E:00:03:41]

[65:002 S:00:04:50 E:00:04:51]

As mentioned above, the handshape of an initialized blend represents a letter of manual alphabet and this handshape is added to lexical sign that already exists in the SL lexicon. Also, the blend sign holds all phonological parameters (except from handshape) of the existing source word. For example, the TID initialized blend PUAN (POINT) is based on the native and lexicalized TID sign SUCCESS. Onehanded SUCCESS is formed with single ASL-Open A handshape moving upward in signing space, but in PUAN (POINT), the ASL-Open A handshape is replaced with P handshape. So, it can be suggested that in addition to their Turkish-influenced phonological form, initialized blends are also typically characterized in terms of the structure of their native source word. Conversely, consider the initialized signs LAZIM (NECCESARY), LISE (HIGHSCHOOL), and LOCAL (CLUB). The crucial problem of this aspect is to determine the actual words, the manual alphabet is fuzzed and how their morphological formation is realized.

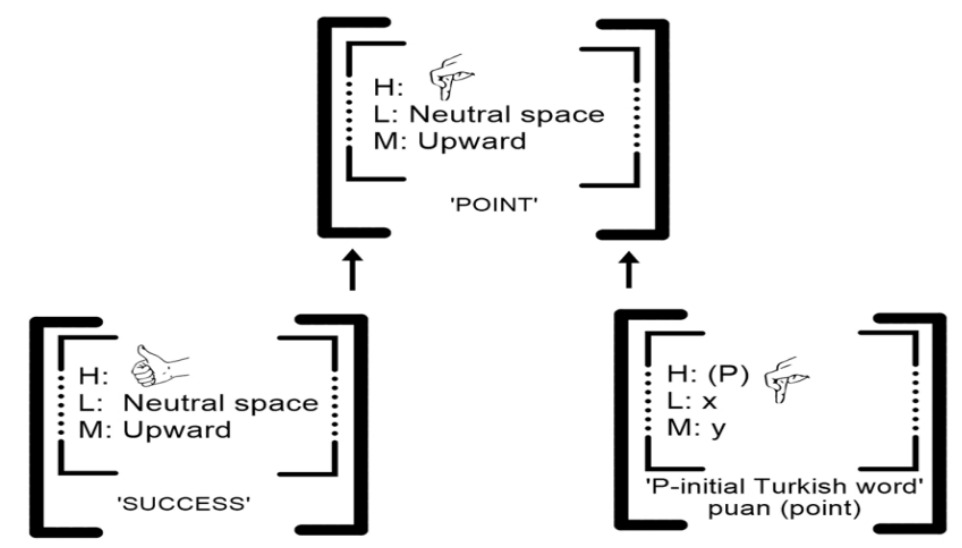

Figure 5. The formation of an initialized blend 'POINT' from schematic constructions in TID

Another interesting property of initialization in TID lexicon is that it includes both initialized sign and initialized blend for the same concept. An example that the initialized sign VITAMIN ${ }^{11}$ signed with

\footnotetext{
${ }^{11}$ VITAMIN, Makaroğlu \& Dikyuva (2017) http://tidsozluk.net/vidz_proc/1667/degiske/1667-01_cr_0.5.mp4
} 
$\mathrm{V}$ handshape moving away from body repeatedly but in initialized blend VITAMIN $^{12}$, the ASL-5 handshape of BODY ${ }^{13}$ source word is replaced with $\mathrm{V}$ manual alphabet (see Figure 6). That the same initialized, borrowed word undergoing different initialization formations also strengthen this assumption.

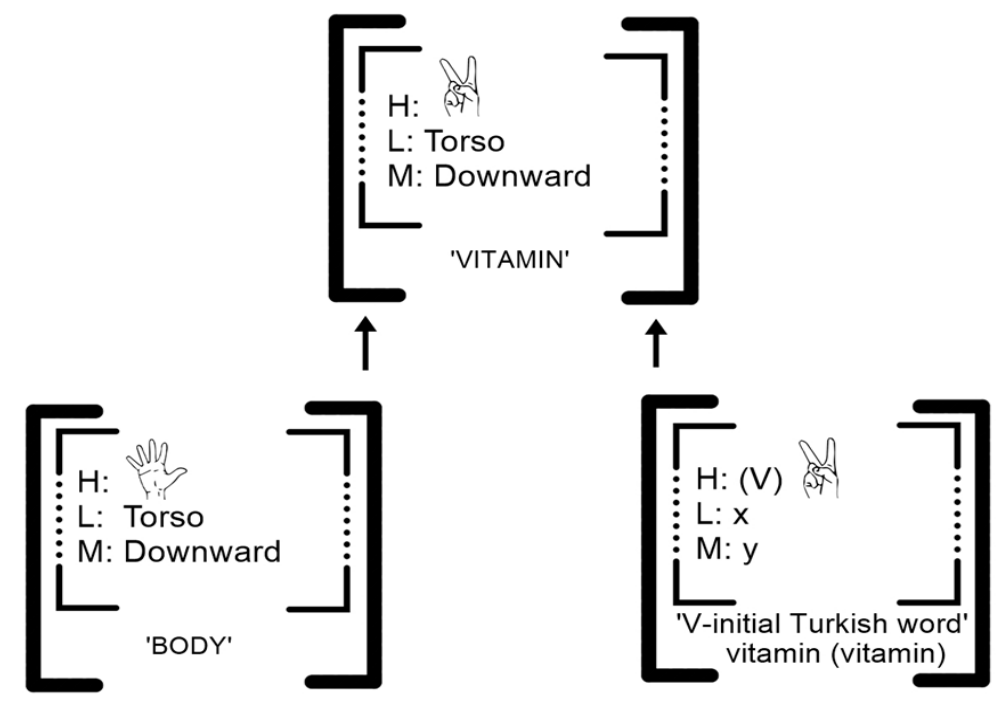

Figure 6. The formation of an initialized blend 'VITAMIN' from schematic constructions in TID

The mapping between form and meaning in initialized blends raises attracted challenges for morphological theory. It is also somewhat surprising that both manual alphabets and actual words show an unexpected interaction under the light of word formation.

\subsection{Simultaneous Blends}

Due to the differences in modality in each type of language production, this study found divergences between the aspects of blending formation in spoken and signed contexts. As widely known, unlike spoken languages that can only make use of the vocal tract, the visual-spatial modality allows SLs to use more than one articulator - that is two hands and nonmanual markers - which are independent in physiological extent. Therefore, two hands can be used to produce two distinct words in simultaneous articulations (Meir et al 2010). In the SL literature, bimanual simultaneity is used in various domains such as topic-comment structures (Perniss 2012), discourse continuum (Liddell 2003) and locative relationships of referents (Engberg-Pedersen 1994). Bimanual simultaneity is also observed in blending formations called "simultaneous blends", that is, all blends of this type are twohanded. In principle, they involve some sort of simultaneity of the source words, one by each hand. Consider the examples below (5):

$\begin{array}{llll}\text { (5) } \text { Sign } 1 & \text { Sign } 2 & \text { Blend } & \\ \text { HOME } & \text { STAYING } & \text { HOME-STAYING } & \text { [72:002 S:00:03:08 E:00:03:09] } \\ \text { HOUR } & \text { LATER } & \text { DELAY } & \text { [35:028 S:00:08:09 E:00:08:10] } \\ \text { ALL } & \text { INSIDE } & \text { ALL-INCLUSIVE } & \text { [01:010 S:00:04:06 E:00:04:07] }\end{array}$

First, let us consider the example in HOME-STAYING in Figure (7) from TID, where the right hand (i.e. dominant hand, henceforth H1) producing the word STAYING and the left hand (i.e. non-dominant

\footnotetext{
${ }^{12}$ VITAMIN, TID Corpus 65:002 S:00:04:50 E:00:04:51]

${ }^{13}$ BODY, Makaroğlu \& Dikyuva (2017) http://tidsozluk.net/vidz_proc/0395/degiske/395-01_cr_0.5.mp4
} 
hand, henceforth $\mathrm{H} 2$ ) producing the word HOME. It should also be mentioned that although two hands refers to two distinct signs, due to phonological constraints in manual simultaneity, only one hand makes specified movement in proper time (see Hendriks 2007: 240; Kimmelman 2015: 228).

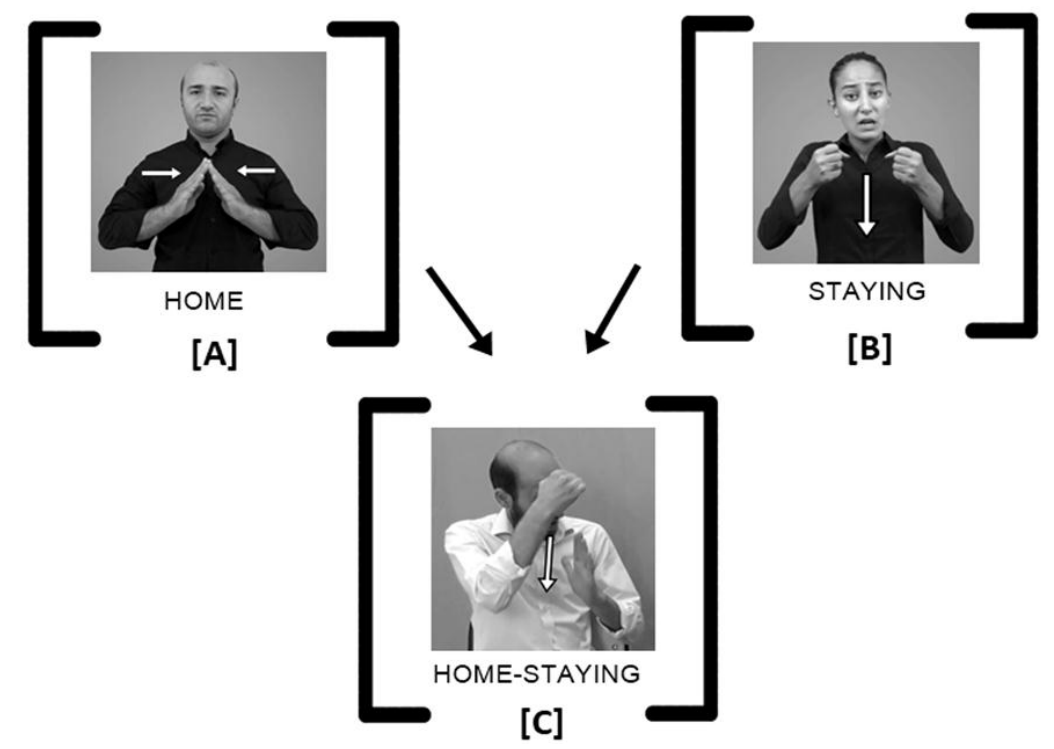

Figure 7. The TID signs (a) HOME ${ }^{14}$ and (b) STAYING ${ }^{15}$ combine to form the blend (c) HOME-STAYING ${ }^{16}$

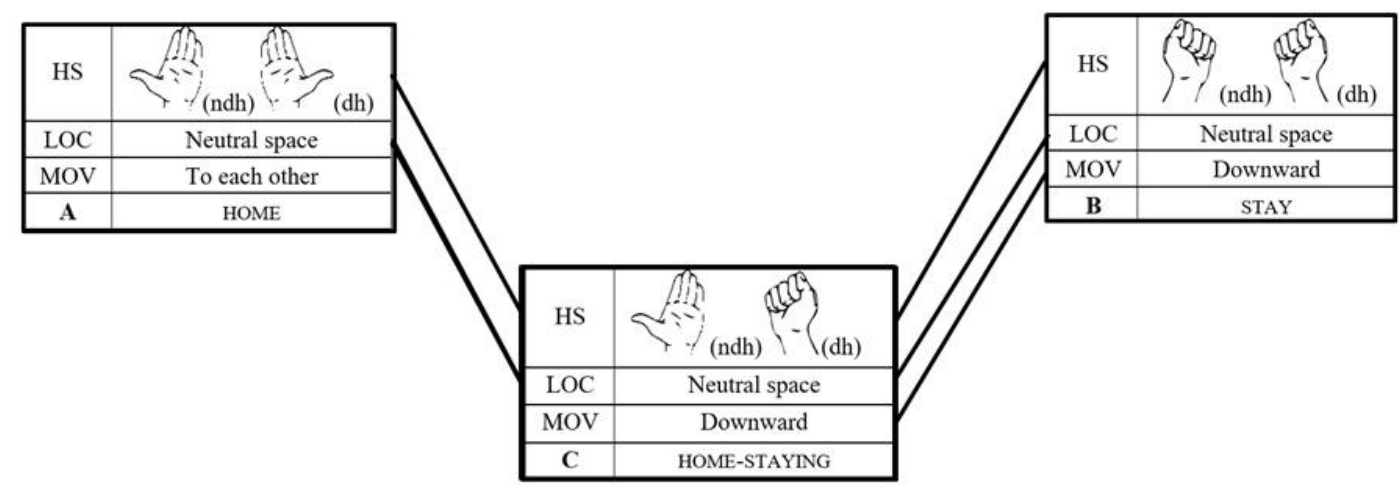

Figure 8. The TİD signs (a) HOME and (b) STAYING combine to form the blend (c) HOME-STAYING

Interestingly, the same patterns of simultaneous blending formation are also attested in initialized signs and they use the more complex form of initialization. The phonological status of initialized signs are dissimilar - that is they are formed using a handshape that is equivalent to the first letter of the words of spoken language - however, they share simultaneous formation in lexical combination. Consider the example of ELEMENTARY-SCHOOL in 9) in TID, where H1 producing the word SECONDARY-SCHOOL and $\mathrm{H} 2$ producing the part (i.e. non-dominant hand) of the word of PRIMARYSCHOOL. This example clearly shows that at least, one of the segmental units of initialized words are seen having two-handed handshapes such as "I" in TiD. Thus, this example reveals quite an interesting aspect of blending formation in signed modality, namely, the possibility of blending formation with units that belong to different handshapes.

\footnotetext{
${ }^{14}$ Makaroğlu \&Dikyuva (2017) http://tidsozluk.net/vidz_proc/0084/degiske/84-01_cr_0.5.mp4

${ }^{15}$ Makaroğlu \&Dikyuva (2017) http://tidsozluk.net/vidz_proc/0445/degiske/445-01_cr_0.5.mp4

${ }^{16}$ HOME-STAYING, TID Corpus 72:002 S:00:03:08 E:00:03:09]
} 


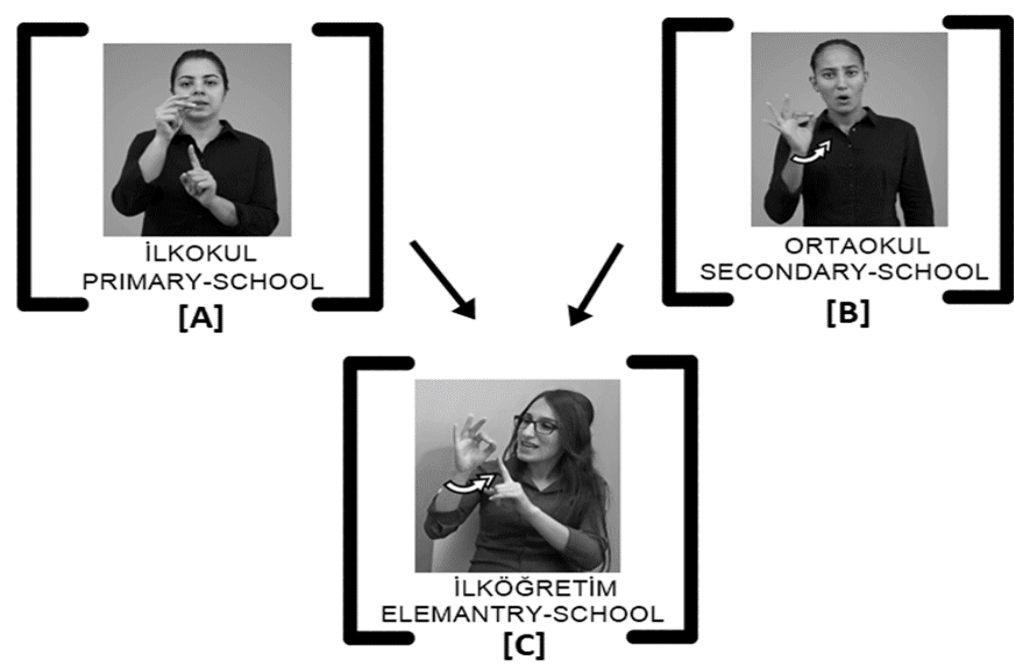

Figure 9. The TID initialized signs (a) PRIMARY-SCHOOL ${ }^{17}$ and (b) SECONDARY-SCHOOL ${ }^{18}$ combine to form the simultaneous initialized blend (c) ELEMENTARY-SCHOOL ${ }^{19}$

With respect to the role of prosodic structure in initialized blend formation as seen in Figure (10), two issues arise. The first is that, at least one of the fingerspelled loan sign has undergone deletion of segments (e.g. H1 deletion) in two-handed alphabets. Second, the link between form and meaning is partially lost. Although this example is interesting according to the phonological interaction of two manual alphabets, and has some kind of morphological motivation, it now has a simultaneous appearance. We leave further analysis and discussion of this example for future research.

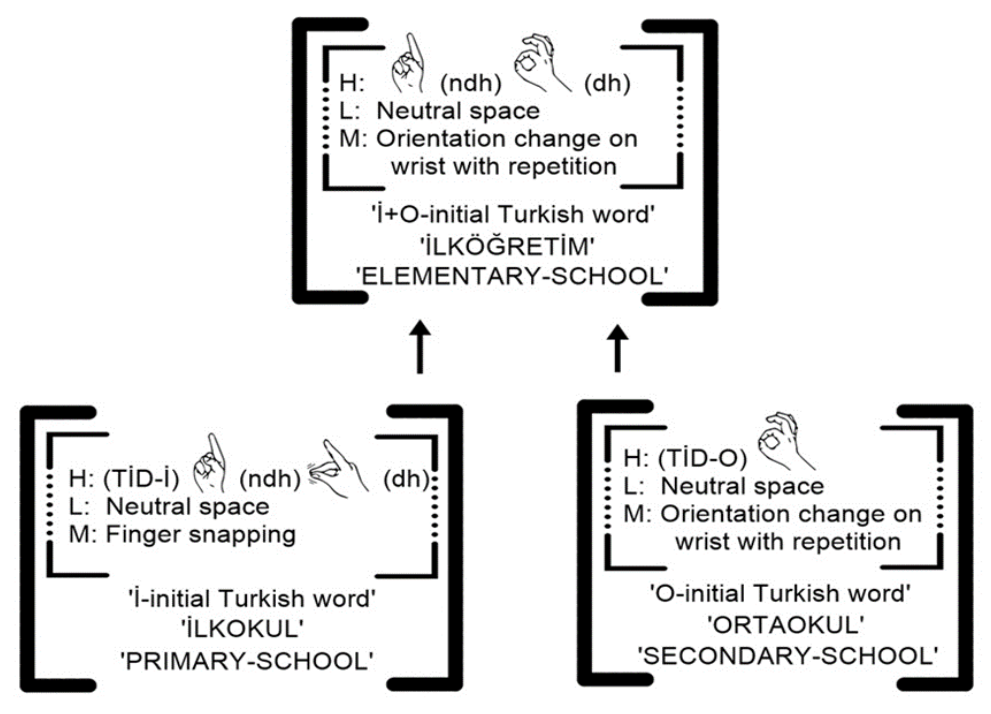

Figure 10. Phonological elements of the TID initialized signs (a) PRIMARY-SCHOOL and (b) SECONDARY-SCHOOL combine to form the simultaneous initialized blend (c) ELEMENTARY-SCHOOL

The phonological difference to complete blends is twofold. First, simultaneous blends hold both handshapes of source words whether they are one-handed or two-handed signs. Second, by handshape features, it can be recovered quite easily and one can clearly identify source words. Even if this type resembles the simultaneous compound in terms of its non-sequential process, they differ sharply from

\footnotetext{
${ }^{17}$ Makaroğlu \& Dikyuva (2017) 'http://tidsozluk.net/vidz_proc/0932/degiske/932-01_cr_0.5.mp4

${ }^{18}$ Makaroğlu \& Dikyuva (2017) http://tidsozluk.net/vidz_proc/0445/degiske/445-01_cr_0.5.mp4

${ }^{19}$ ELEMENTARY-SCHOOL, TID Corpus [53:008 S:00:01:38 E:00:01:39]
} 
each other in phonological aspects. For example, canonically two-handed signs can be source words (e.g. HOME and STAYING in TID) but then simultaneous compounds are limited to one-handed or preferable two-handed signs (see Meir et al 2010). Although these types of compounds include full forms and one of the combining signs changes to the H2 (Göksel \& Pfau 2017), certain parts of the source words is enough for the structural fusion of two lexemes (e.g. non-dominant hand of HOUR in DELAY). According to current analysis, since the certain phonological parts (not full forms) of the two different source words create a single sign, this type of morphological formation should be characterized as blending not compounding. To conclude, the simultaneous blends described in this section are necessarily unique to the signed modality. In addition, this formation is not a frequent type of blending in our data but more formational aspects can be obtained to get a categorization peculiar to SLs.

\section{Result of Blending Formation and Formal Properties}

\subsection{Prosodic structure}

Phonological processes of blending formation are less-researched compared to compounds in the SL phonology literature. It has been found that in many SLs, it is very common for blends to undergo specific prosodic changes in relatively consistent and predictable ways. As a result of numerous phonological changes in formation that can happen, a blend may end up looking very much a monosyllabic simplex sign. With respect to the prosodic structure in signed blends, blends are reduced forms, in the sense that they tend to be a monosyllabic unit with only one movement. The phonological characteristics of lexical blends in TID are briefly presented below.

- Deletion of repetition: The repeated phonological elements of source words are lost in the formation of a blend. For example in ALL-INCLUSIVE, the source word INSIDE having repeated element is represented with a single path movement.

- Changes in handshape: In the alignment of source words, the handshape feature of the first word effects the second one as in OLDER-BROTHER. ASL-open A handshape of MALE assimilates to ASL-5 handshape of OLDER. In some examples as in ALL-INCLUSIVE, lexical blends hold both of the handshape at a certain part of the syllable (i.e. onset and offset). The ASL-5 handshape of ALL can change to ASL-flat O handshape of INSIDE within a single syllable.

- Changes in location: Similar to handshape assimilation, location properties of one of the source words can spread to another one in blend formation. When we look at the location assimilation that are intrinsically attested in type of root blends. For example, in UNCERTAINTY, the source word QUESTION deviates from the neutral space to head and in SECRET, the source word LOCK deviates from the $\mathrm{H} 2$ to mouth.

- Deletion of H1: Regarding simultaneous blends, it has been observed that the H1 of the twohanded source word is deleted in phonological formation. For example, in blend HOMESTAYING, H1 of the source word HOME (Type 1 in terms of Battison's Typology - two active hands with the same handshape performing the same movement) is lost and in blend DELAY, H1 of the source word HOUR (Type 3 in terms of Battison's Typology - two-handed signs with an active and a passive hand, each having a different handshape) is deleted (see Battison, 1978 for Battison's typology). 


\subsection{Iconic motivation}

Turning now to the non-arbitrary links, iconic relationships between meaning and form are far more prevalent in SLs, where the visual-manual modality holds many more devices for non-arbitrary mappings (e.g. Taub 2001; Perniss et al 2010; Occhino 2017; Meir \& Tkachman 2018). That is, iconic motivation can be easily found in many signs (Klima \& Bellugi 1979). Obviously, SL lexicons contain partly or mostly iconic contrary to spoken languages having limitation on acoustic iconicity. Boyes Braem (1986) estimates that at least a third of lexical signs in DSGS have iconic (motivated) relations. Recent studies in SLs shows that productive and pervasive iconicity should not basically be defined as a similarity between language form of sign and its real-world referent, and that it also displays an important role in its both semantic and morphological forms (see Schlenker 2014, 2018).

At first glance, we attested various iconic relationships between meaning and form in blending formation and some blends are iconic to different degrees. Although iconic blends present a challenge for the traditional division between the morpho-phonological units, some examples would be much easier to analyse in terms of their formational aspects. In the first example, as illustrated in Figure (11), iconicity makes a link from linguistic form to human experience (i.e soccer referee signaling a penalty) and manual alphabet (i.e is equivalent to the first letter of Turkish word, penalt1). Thus, the blend sign PENALTY visually resembles the act of showing penalty mark and this shows a unique type of interaction between manual alphabet and pointing gesture in the grammar of TiD. This example also implies that certain categories of blending formation are widely predictable due to iconic motivation. As Wilcox (2004:123) highlights that iconicity is not a simple relation between the objective aspects of a situation and the objective aspects of articulators. Rather, the iconic mapping is set between interpretations of real-word scenes and interpretations of forms in a cognitive way.

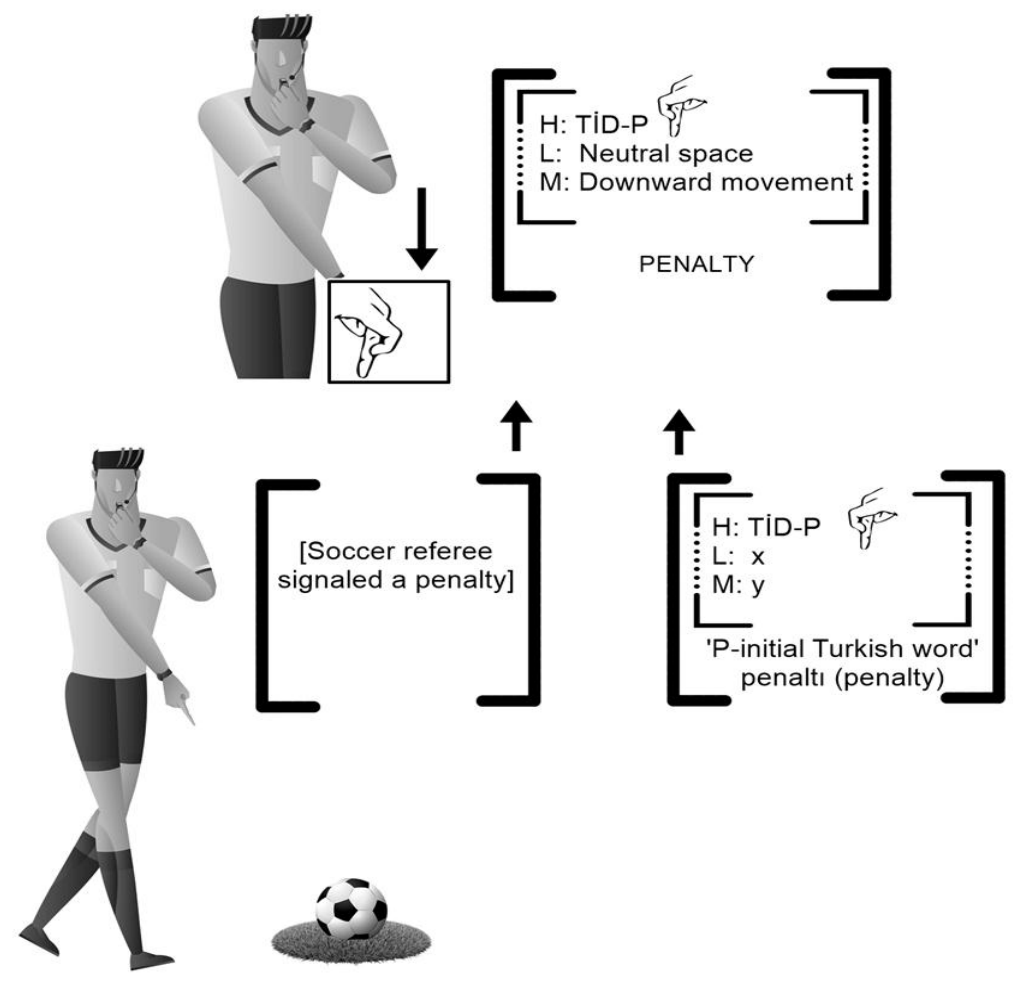

Figure 11. The iconic motivation in the formation of PENALTY

Building on iconic mappings in the blending formation, it can be suggested that the pictorial properties of blends must not be limited to initialized signs having manual alphabet. As in (12), one 
can see that number handshapes on the shoulders make an excellent military ranks symbol of the Turkish Army and signers in fact use number handshapes to map grades on the shoulder boards. Traditionally, manual numbers articulated in neutral space or unmarked locations have been assumed not to create form-meaning mappings. However, the blend sign sergeant visually shows the specific construction in which the combination of number handshapes and (shoulder) position provides the motivated mapping.

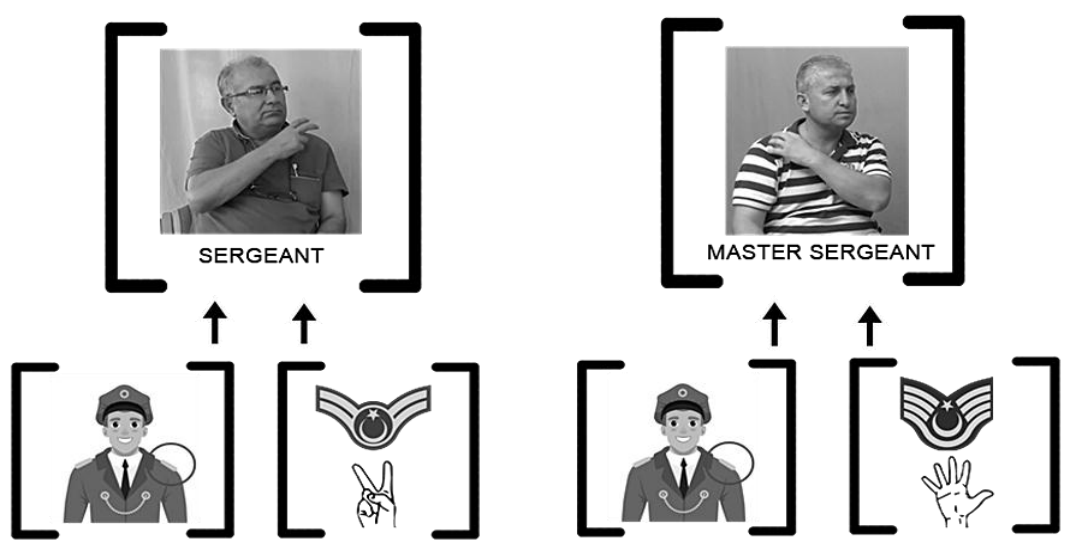

Figure 12. The iconic motivation in the formation of SERGEANT ${ }^{20}$ and MASTER-SERGEANT ${ }^{21}$

The observations here lead to the conclusion that arbitrariness play formational roles in blending formation in TiD. Building on this view, any type of handshape - manual alphabet or number signs can be defined as an executor in these iconic mappings. The reason for this perspective is that, iconicity is rooted in the

\subsection{Alignment of base words}

Another issue which will be addressed in this study concerns the order of source words where new TiD blends are created in linear formation. The attempts to sort the alignment of based words show signed blends to be a largely unpredictable category especially in proper types due to sub-lexical features of SLs. The difficulties in analysing alignment patterns of lexical blends stem from simultaneous morphology. Since both non-concatenating formation and visual-spatial modality are essential characteristics of SLs. However, this study suggests that limited classifiable regularities can be found in proper blend types having at least two locations or handshapes. Because these blends have two distinct locations in the onset and offset position of the monosyllabic form. Thus, blending sign involves combining location parts of source words in a linear order. Consider the examples below (6):

(6) Sign 1

$\begin{array}{ll}\text { YEAR (teeth) } & \text { BEFORE (shoulder) } \\ \text { MONEY (covered-T) }^{\text {MUCH (ASL-5) }}\end{array}$

Sign 2

EXPENSIVE(covered-T > ASL-5)
(Location)

(Handshape)

Similar to left-headed compounds in TİD such as DELICIOUS (TASTE+GOOD), UGLY (FACE+BAD), STUBBORN (HEAD+HARD) (Dikyuva et al 2017), the order of source words in these blends is more likely to be syntactically determined. So, the adjective source word is commonly seen in the second position of the blend formation.

\footnotetext{
${ }^{20}$ SERGEANT, TIDD Corpus [10:008 S:00:01:04 E:00:01:05]

${ }^{21}$ MASTER-SERGEANT, TİD Corpus [10:021 S:00:05:54 E:00:05:55]
} 


\section{Discussion and Conclusion}

In SL literature, it is known that investigating derivational mechanism has a number of potential challenges and roughly speaking, the studies mainly have focused on the proper constructions (e.g. verb-noun pairs, compounds) (see Pfau \& Göksel 2017). However, recent studies have shown that describing complexity characteristics of blending formation in lexicon can answer many critical questions on derivational morphology. There have been a number of studies on the descriptive and theoretical aspects of derivation in TiD literature (e.g. Kubuş 2018; Taşçı 2012; Dikyuva, Makaroğlu \& Arık, 2017; Taşçı \& Göksel 2018; Makaroğlu 2020). However, as we know, no examination of the blending formation has been carried out for the TID context.The present paper provides a first systematic investigation of the categorical aspects of lexical blends in TID, building on previous work developed by Lepic (2016).

Regardless of language modality, blending is a basic morphological category of human languages. In other words, natural languages (spoken or signed) use various morpho-phonological strategies to create a one-word unit formed from the structural fusion of two (or possibly more) lexemes. In this exemplary account of lexical blending, the pattern of blend types in TID (see Table 1) generally follows the patterns found in ASL analysed in Lepic (2016)'s framework. In the context of our classification, this proposal makes the novel templatic blend-operation, in which morphological patterns in blending can be formalized systematically. Although the findings concerning complete blends are mainly in line with previous studies on spoken language (c.f. Arndt-Lappe \& Plag 2013; Mattiello 2013, 2019; Beliaeva 2019), the pattern of blend formation in TiD expands the blending typology known from spoken language in their interesting ways (i.e. non-actual or borrowed source units, simultaneous construction, iconic motivation), all of which expand our understanding of the blending phenomena in natural language. So, it can be concluded that blending types in signed languages hold much more formational possibilities than could be predicted in the classification on blending constructions of spoken languages. Leaving theoretical issues aside, it is also seen that the visual-spatial modality has a direct impact on almost every aspect of blending formation.

Table 1. Rank frequency profile of blend types in TiD Corpus

\begin{tabular}{lcc}
\hline Blend Type & Number of Blends & Percentage \\
\hline Root blends & 61 & $56,0 \%$ \\
Complete blends & 34 & $31,2 \%$ \\
Simultaneous blends & 8 & $7,3 \%$ \\
Initialized blends & 5 & $4,6 \%$ \\
\hline
\end{tabular}

As can be seen in Table 1, the most productive type of signed blending to be that of which is formed with the structural fusion of a fully lexicalized sign and an abstract root (i.e. location) with specific meaning, e.g. ILLUSION< (eye) + REVERSE. It accounts almost for one third of the whole blending dataset. The second most productive type is root blends which formed with two fully lexicalized source words, e.g. OLD < YEAR + BEFORE. The other two types (i.e. simultaneous and initialized blends) correspond to a relatively small percentage of the dataset.

To conclude, it is evident that further research on word creation in signed modality can benefit from the formal descriptions provided by lexical blends mentioned here. More broadly, the distributional analysis clearly shows that by attempting to define the formal features of lexical blends, more description can be obtained to understand the blending formation phenomena in a crosslinguistic way. 


\section{References}

Aronoff, M., Meir, I., \& Sandler, W. (2005). The paradox of sign language morphology. Language 81, 301-344.

Arndt-Lappe, S., \& Plag, I. (2013). The role of prosodic structure in the formation of English blends. English Language and Linguistics, 17(3), 537-56.

Beliaeva, N. (2019). Blending creativity and productivity: on the issue of delimiting the boundaries of blends as a type of word formation. Lexis Journal in English Lexicology, 14, 1-22.

Bat-El, O. (1996). Selecting the best of the worst: The grammar of Hebrew blends. Phonology 13, 283-328.

Battison, R. (1978). Lexical Borrowing in American Sign Language. Linstok Press, Silver Spring, MD (Reprinted 2003, Linstok Press).

Bauer, L., Lieber, R., \& Plag, I. (2013). The Oxford reference guide to English morphology. Oxford: Oxford University Press.

Belsitzman, G. \& Sandler, W. (2016). Motivated phonological templates in Sign Language. Proceedings of the Mediterranean Morphology Meetings (MMM), 10, 31-44.

Boyes Braem, P. (1986). Two aspects of psycholinguistic Research: iconicity and temporal structure. In: B. T. Tervoort, (ed.), Signs of life: Proceedings of the Second European Congress on Sign Language Research (pp. 65-74). Amsterdam: Publication of the Institute for General Linguistics, University of Amsterdam 50.

Brentari, D. (2002). Modality differences in sign language phonology and morphophonemics. In, R. Meier, D. Quinto-Pozos \& K. Cormier (eds.), Modality in language and linguistic theory (pp. 3564). Cambridge University Press; Cambridge, UK.

Dikyuva, H., B. Makaroğlu \& E. Arık. (2017). Turkish Sign Language Grammar. Ministry of Family and Social Policies Press: Ankara.

Dressler W. U. (2000). Extragrammatical vs. marginal morphology. In U. Doleschal \& A. M. Thornton (eds), Extragrammatical and marginal morphology (pp. 1-10). München, Lincom Europa.

Engberg-Pedersen, E. (1994). Some simultaneous constructions in Danish Sign Language. In M. Brennan \& G. Turner (eds.), Word-order issues in sign language (pp. 73-87). Durham, England: International Sign Linguistics Association.

Fernald, T. \& Napoli, D. J. (2000). Exploitation of morphological possibilities in signed languages: comparison of American Sign Language with English. Sign language and linguistics, 3, 3-58.

Göksel, A. \& Pfau, R. (2017). Compounding. In: J. Quer, C. Cecchetto, C. Donati, C. Geraci, M. Kelepir, R. Pfau \& M. Steinbach (eds.), Sign Gram Blueprint: A guide to sign language grammar writing (pp. 169-188). Berlin: Mouton de Gruyter.

Hendriks, B. (2007). Simultaneous use of the two hands in Jordanian Sign Language. In Vermeerbergen et al. (eds.), Simultaneity in signed language: Form and function (pp. 237-255). Amsterdam: John Benjamins.

Jeremić, J. D., \& Josijević, J. (2019). To blend so as to brand: a study of trademarks and brand names. Lexis Journal in English Lexicology, 14. 
Kemmer, S. (2003). Schemas and lexical blends. In H. Cuyckens, T. Berg, R. Dirven and K. Panther (eds.), Motivation on language: studies in honor of Günter Radden (pp. 69-97). Amsterdam \& Philadelphia: John Benjamins.

Kimmelman, V. (2015). Multiple tiers, multiple trees. In Proceedings of CLS 49 (pp. 225-238). Chicago: Chicago Linguistic Press.

Klima, E. S. \& Bellugi, U. (1979). Iconicity in signs and signing. In E. S. Klima \& U. Bellugi (eds.), The signs of language (pp. 9-34). Cambridge, MA: Harvard University Press.

Kubuş, O. (2008). An analysis of Turkish Sign Language (TID) phonology and morphology (Master's thesis). Middle East Technical University, Ankara.

Lehrer, A. (2007). Blendalicious. In J. Munat (ed.), Lexical creativity, texts and contexts (pp. 115133). Amsterdam/Philadelphia: Benjamins.

Lepic, R. (2016). Lexical blends and lexical patterns in English and in American Sign Language. In J. Audring, F. Masini \& W. Sandler (eds.), Online proceedings of the tenth Mediterranean Morphology Meeting MMM10 (pp. 98-111).

Liddell, S. (2003). Grammar, gesture, and meaning in American Sign Language. Cambridge: Cambridge University Press.

Makaroğlu, B. (2018). Türk İşaret Dilindeuyum: Şablonbiçimbilimaçısındanbirinceleme (Doctoral dissertation). Ankara University, Ankara.

Makaroğlu, B. (2020). TỉD'de Türetim Olgusuna Bürünsel Biçimbilim Açısından Bakış. DEÜ Edebiyat Fakültesi Dergisi, 7(2), 305-339.

Makaroğlu, B. \& Dikyuva, H. (2017). The contemporary Turkish Sign Language dictionary. Ankara: The Turkish Ministry of Family and Social Policy. Retrieved from http://tidsozluk.net.

Mattiello, E. (2013). Extra-grammatical morphology in English. Abbreviations, blends, reduplicatives, and related phenomena. Berlin/Boston: Mouton de Gruyter.

Mattiello, E. (2017). Analogy in word-formation. A study of English neologisms and occasionalisms. Berlin/Boston: Mouton de Gruyter.

Mattiello, E. (2018). Paradigmatic Morphology splinters, combining forms, and secreted affixes. SKASE journal of theoretical linguistics, 15(1).

McCarthy, J. (1979). Formal problems in semitic phonology and morphology (Doctoral dissertation). MIT, Cambridge.

McCarthy, J. (1981). A prosodic theory of nonconcatenative morphology. Linguistic inquiry, 12, 373418.

Meir, I. (20129. Word classes and word formation. In R. Pfau, M. Steinbach \& B. Woll (eds.), Sign language: An international handbook (pp. 77-111). Berlin: Mouton de Gruyter.

Meir, I., Aronoff, M., Sandler, W., \& Padden, C. (2010). Sign languages and compounding. In S. Scalise \& I. Vogel (eds.), Compounding (pp. 301-322). Amsterdam: John Benjamin

Meir, I., \& Tkachman, O. (2018). Iconicity. In M. Aranoff (eds.), Oxford Research Encyclopedia of Linguistics. Oxford: Oxford University Press.

Mirus, G., Fisher, J., \& Napoli, D. J. (2012). Taboo expressions in American Sign Language. Lingua 122(9), 1004-1020. 
Occhino, C. (2017). An introduction to embodied cognitive phonology: Claw-5 handshape distribution in ASL and Libras. Complutense Journal of English Studies, 25, 69-103.

Östling, R., Börstell, C., \& Courtaux, S. (2018). Visual iconicity across sign languages: Large-scale automated video analysis of iconic articulators and locations. Frontiers in psychology, 9, 725.

Perniss, P. (2012). Use of sign space. In R. Pfau et al. (eds.), Sign language: An international handbook (pp. 412-431). Berlin: Mouton de Gruyter.

Perniss, P., Thompson, R. \& Vigliocco, G. (2010). Iconicity as a general property of language: evidence from spoken and signed languages. Frontiers in psychology, 1, 227.

Pfau, R., \& Göksel. A. (2017). Derivation. In J. Quer, C. Cecchetto, C. Donati, C. Geraci, M. Kelepir, R. Pfau \& M. Steinbach (eds.), Sign Gram Blueprint: A guide to sign language grammar writing (pp.188-200). Berlin: Mouton de Gruyter.

Sandler, W., \& Lillo-Martin, D. (2006). Sign language and linguistic universals. Cambridge: Cambridge University Press.

Schlenker, P. (2014). Iconic features. Natural language semantics, 22(4), 299-356.

Schlenker, P. (2018). What is super semantics?. Philosophical Perspectives, 32(1), 365-453.

Taşç1, S. S. (2012). Phonological and morphological aspects of lexicalized fingerspelling in Turkish Sign Language (TID) (Master's Thesis). Boğaziçi University, Istanbul.

Taşç1, S. S., \& Göksel, A. (2014). The morphological categorization of polymorphemic lexemes: A study based on lexicalized fingerspelled forms in TiD. Dilbilim Araştırmalarl, Special Issue in Honor of Prof. A. Sumru Özsoy, 165-180.

Taşç1, S. \& Göksel, A. (2018). Native compounds in TID: A classification based on headedness. Dilbilim Araştırmaları Dergisi, 29(1). 1-28.

Taub, S. F. (2001). Language from the body: Iconicity and metaphor in American Sign Language. Cambridge University Press.

Wilcox, S. (2004). Conceptual spaces and embodied actions: cognitive iconicity and signed languages. Cognitive Linguistics, 15(2), 119-147.

\section{AUTHOR BIODATA}

Bahtiyar Makaroğlu holds an MA and a PhD in Linguistics from Ankara University, Turkey. Currently, he is working as a Research Assistant at the Department of Linguistics, Faculty of Letters and Coordinator at the Turkish and Foreign Language Applied and Research Centre (TÖMER) at Ankara University, Turkey. Between 2018-2019, he was visiting scholar (Post-doc) at the University of Pompeu Fabra, Spain. He is specialized in morphology, corpus linguistics and sign language assessment and published the several works include books and journal articles on sign language teaching, sign language grammar in Turkey, Europe and the US. For 8 years now, he has involved in EU and National projects and worked as PI, researcher, editor, key expert and research assistant. 